\title{
Improving Employee Well-Being by Means of Virtual Reality - REALEX: An Empirical Case
}

Pretsch, J.

ERC Experience Research \& Consulting

Pretsch, E.

Saretzki, J.

Kraus, $\mathrm{H}$.

Grossmann, G.

\section{Abstract}

The present paper seeks to analyse how a virtual reality system can foster employee well-being at the workplace. In order to answer the research problem, whether such a system can benefit employees in regards to their well-being, stress perception and relaxation, an empirical case study was conducted. Relevant literature both on the advantages of virtual reality systems in general and on different approaches to fostering employee well-being are displayed and discussed within the paper, leading up to a description of the methodology. Based on a sample of 52 participants from Germany, Austria and Croatia an empirical study with a quantitative, preand post-study approach was conducted. Participants were assessed in regards to their initial stress perception, before they used either the REALEX system (a VR based relaxation tool displaying natural landscapes in a virtual reality setting) or a video streaming service on a classical display. The statistical analyses revealed that the usage of the REALEX system was able to significantly improve participants' stress perception and wellbeing. In doing so it - also significantly - exceeded the positive effect that the control setting (video streaming) had in these regards. Potential limitations of the study are presented and recommendations both for practical work in the field of human resource management and for scientific research are deducted.

Keywords: Improving, employee, well-being, Virtual Reality, REALEX

\section{Introduction}

Problem Statement

For the last decades, a constantly growing intensification of all life spheres can be observed, especially work-related ones. Due to such major trends as the establishment of free markets, globalization, constant exposure to multiple information sources and digitization, the impact on societal mental well-being has grown dramatically (Tuomi, Vanhala, Nykyri \& Janhonen, 2004). While on the one hand being considered as advantages of contemporary society and sources of potential opportunities, these aspects can act as sources of constant stress when managed poorly (Vasantha \& Reddy, 2017).

Results of the EU Labour Force Survey prove that over the course of 8 years (1999-2007) 28\% of European workers confirmed that they have been affected by psychosocial risk factors, with "too little time and too much work" being the main contributing factor (European Commission, 2010). According to the data of European Commision (2010) "stress, depression and anxiety" have been reported as the most serious work-related health problems. 
Lasting exposure to stress, depression and anxiety causes significant problems at individual, organizational and societal levels. Thus, when the level of responsibility and amount or level of job-related tasks are significantly exceeding employees qualification, capability or resources, an employee becomes affected by stress factors (Thoondee \& Oikonomou, 2017). In a short-term perspective stress leads to such health problems as general tiredness, headaches, irritability or frequent mood swings. Long-term consequences of stress lead to more severe problems such as cardiovascular problems, immune system problems, diabetes, and of course depression and anxiety (Michie, 2002).

On organizational level stress leads to productivity decline, higher levels of absenteeism, staff turnover and general deterioration of the working climate. According to the data provided by the European Working Conditions Survey, already in 2007 around 40 million people were affected by work related stress. Similarly, in 2009 between 50 and $60 \%$ of all lost working time was caused by stress related factors (Eurofound, 2012).

In spite of the fact that many organizations seem to share an understanding of an equation "happy employee = productive employee", in reality most of them consider investments only in the areas directly related to improvement of financial indicators (Nielsen et al., 2017). As Luthans and Youssef (2004) notice, many companies struggle to demonstrate how investments in human resources can be capitalized not only in the short, but also in a long-term perspective. In the conditions of changing demographic, growing competitions, fast changing societal demands towards an organization and a working place, as well as often nonstable economic and political situations, investment in employees' well-being and development becomes risky and often unaffordable for many companies. At the same time in order to ensure employees' well-being at the working place, a company should take efforts on several different levels (Nielsen et al., 2017). By means of efficient HRM practices and constructive and supportive leadership style, such as transformational leadership, companies should establish a healthy and productive spirit within an organization on both individual and group level. If a company fails to comply on one of the levels, employees' well-being will inevitably suffer (Tuomi, Vanhala, Nykyri \& Janhonen, 2004). Thus, if an organization has inefficient HRM practices, they might disrupt a healthy environment even within an organization with an initially constructive group dynamic. Similarly, toxic leadership styles, which foster such destructive practices as bullying and harassment, lack of transparency, constant overworking and unhealthy competitions, will nullify existing healthy practices and result in an atmosphere with a high level of stress and anxiety among its employees (Darling \& Heller, 2011).

Thus, ensuring employees' well-being is a challenging task for an organization, since it requires an understanding of the fact that in order to ensure organizational success in a long-term perspective, a company has to value its employees both as workers and as individuals. At the same time, in order to create a healthy atmosphere within an organization, a company has to ensure healthy working practices on individual, group, organizational levels, as well as a constructive and supportive leadership style (Nielsen et al., 2017).

In the current research we study the efficiency of virtual reality applications for employees' stress reduction and prevention of anxiety and depression in an office environment. Since the role and importance of technological advancements in a working and everyday life grow steadily, its application for creating a better and healthier working environment attracts more interest (Tuomi, Vanhala, Nykyri \& Janhonen, 2004). While virtual reality has been applied in some companies for employees' training and simulation of real-life situations, such as handling customers' complaints, its application with a purpose of on spot in-office relaxation has rarely been studied (Thoondee \& Oikonomou, 2017).

As it was mentioned, in order to maintain employees' well-being, a company should make efforts on several levels. In this regard, application of virtual reality is not proposed as a remedy for all evil, but rather as one of the solutions for dealing with the increasingly growing problem of stress and anxiety in a working environment. While solving a specific problem making a relaxation and mental off-load in the office more available - application of such technological advancement for employees' well-being carries some certain characteristics of an employer as well. Application of virtual reality in the office for enabling employees' mental off-load and relaxation, apart from creating a more relaxed and productive environment, 
also characterises an organization as an employer with human-oriented HRM practices, that is progressive enough to consider an application of virtual reality technologies and caring enough to use these technologies for improving well-being of its own personnel. Benefits from virtual reality application by an employer for employees'relaxation in the office can, thus, be divided into direct and indirect ones (Figure 1).

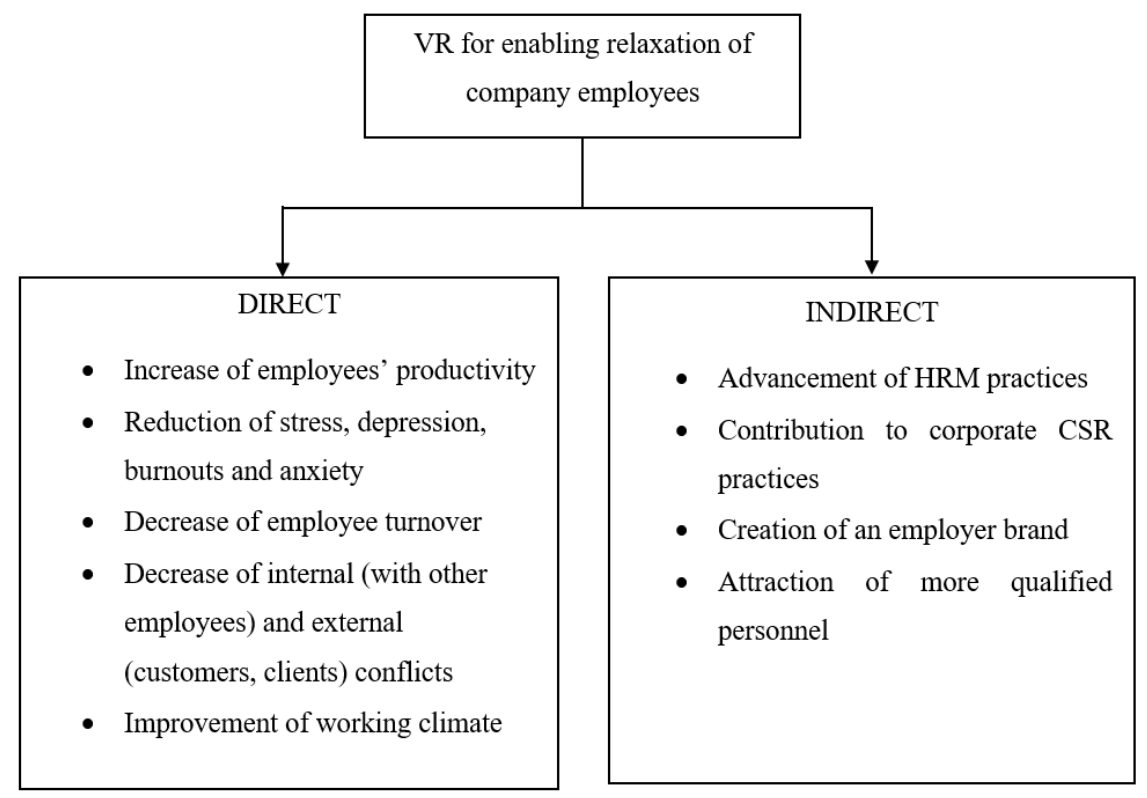

\section{Literature Review}

\section{The usage of Virtual Reality for relaxation}

The first studies on VR as a new way of treatment various disorders started to appear in the beginning of the $90 \mathrm{~s}$. Most of VR-related studies back then were aimed at the exploration of VR in treatment of various phobias, such as claustrophobia (Booth \& Rachman, 1992), arachnophobia (fear of spiders), acrophobia (fear of heights) (Rothbaum et al., 1995), fear of driving and public speaking, eating disorders, post-traumatic stress disorders and others. The results of most studies proved significant efficiency of VR in treatment of mentioned conditions, with most of the participants reporting significant decrease of anxiety, fears and related disorder symptoms. VR, thus, has proved to be an efficient mechanism for the treatment of various disorders in clinical conditions.

With proliferation of VR technologies, as well as its wider availability, studies regarding VR effect on other spheres of society started to spread outside clinical psychology. Thus, with a growing danger posed by stress in a contemporary society, there can be observed a growing interest towards exploration of VR effects on treatment of stress, anxiety and depression.

In a study conducted by Baños et al. in 2013, the authors tested the ability of VR to induce positive emotions, such as joy and relaxation on clinical patients. After using VR during four sessions with a duration of 30 mins each for one week, all patients demonstrated an increase in positive emotions and decrease in negative emotions, such as sadness and anxiety. A similar study by Herrero, Garcia-Palacios, Castilla, Molinari and Botella (2014) revealed that VR used as a part of psychotherapy for patients with a fibromyalgia syndrome leads to an increase of such positive emotions as joy, surprise, vigor and calmness, as well as increases self-motivation and efficacy. Results of these findings are supported by VR efficacy studies also with non-clinical samples. Thus, Serrano, Baños and Botella (2016) found that the use of VR is efficient 
even with people who do not have any initial anxiety or depression problems and that application of VR can increase a level of relaxation even in cases when it is initially high.

Since work related stress and its alarmingly negative impact on the work productivity of office employees is growing fast and steadily, mental relaxation for office employees is becoming crucial for both workers' mental health protection and for employers as a way for keeping productivity of their companies stable. The interest towards efficiency of VR application in offices as a way of decreasing work-related stress is increasing, even though the number of related studies is very low (Thoondee \& Oikonomou, 2017).

A study aimed at researching efficiency of VR in dealing with stress at work was conducted by Thoondee and Oikonomou (2017) with the participation of 32 office employees of various age groups. The study consisted of two modes - pure VRbased relaxation and a mixed mode. During the first mode all the participants were proposed to wear VR reality glasses showing them natural landscape scenes. After the relaxation session all the participants were asked to evaluate their VR experience using a questionnaire. As a result, $28.1 \%$ told that they felt relaxed after their VR session, while $71.9 \%$ of employees reported that they were definitely relaxed. Beside, $93.9 \%$ wanted to use VR glasses again and $100 \%$ told, they would recommend it to someone else (Thoondee \& Oikonomou, 2017). In the second part of an experiment authors tried blend in some of VR elements into office activities. Thus, some VR element were assigned to specific office routing - for example, an appearing flower was indicating a new e-mail, while a changing weather logo was meant to attract attention towards a beginning meeting. An idea of blending VR elements into daily working activities was also positively assessed by the employees as stress reduction measures (Thoondee \& Oikonomou, 2017).

One of the reasons why VR systems seem to do such a good job at contributing to relaxation and improving mood-related outcomes lays in the deep immersion VR based systems offer (Slater \& Sanchez-Vives, 2016). Slater and Sanchez-Vives (2016) argue, that because of this strong immersion effect offered by VR systems they might have a strong impact on peoples' lives - given that they are used in the right setting with the right circumstances, as the authors summarize. This is also pointed out by Makransky, Terkildsen and Mayer (2019) who describe that the usage of virtual reality (in a learning setting) can add to a feeling of presence during the process.

\section{Approaches to fostering employee well-being}

Employee well-being is a concept that spreads further than only taking care of employees' health, but also includes the creation of an environment in which people enjoy their work and that fosters healthy relations within an organization. Even though there is no existing consistency in regard to the definition of well-being as a concept, there is a relatively stable set of elements constituting the term. Well-being at work is defined by multiple factors, including those that are directly related to an organization and those outside of immediate organizational environment. Thus, factors defining workforce well-being from within an organization include such aspects as organizational environment and employees' relations, management practices, general workload and distribution of responsibilities, wage level, possibility for taking own decisions by employees. In organizations where employees constantly experience work overload, have lack of control over their own decisions or their skills do not match their responsibilities, level of workforce stress and associated mental health disorders such as anxiety and depression, is much higher than in organizations with a healthy working climate.

Considering additional outside-an-organization factors, such as general economic or political situations, that pose an additional pressure on an individual, organizations should take particular care of their employees well-being, if they want to avoid burnouts, staff turnover and, as a result, a declined productivity. 


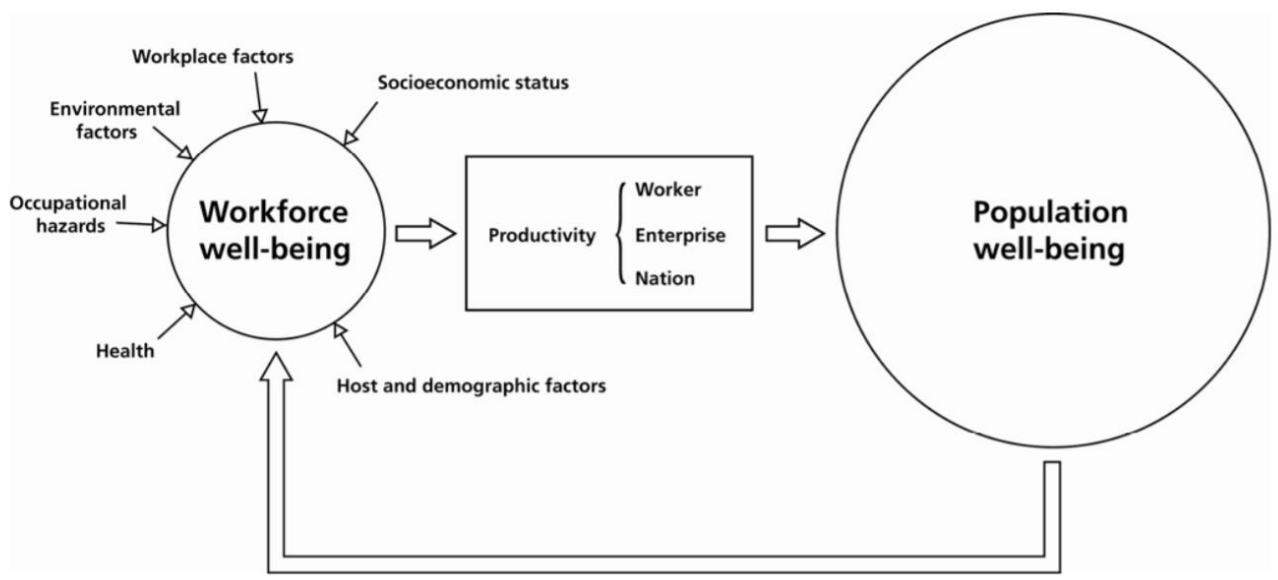

Figure 2. Relationship between workforce well-being, productivity and population well-being (Source: Schulte \& Vainio, 2010).

As an individual does not exist outside the society, it is important while developing measures for promotion of employees' well-being to consider measures at organizational and wider societal levels (Schulte \& Vainio, 2010).

In their research Nielsen et al. (2017) assess an importance of supporting employees' well-being on four levels: individual, organizational, group and leader level. After conducting an analysis of 84 studies, authors concluded that most of them explore workforce well-being support and performance on an organizational level (Nielsen et al., 2017). The most crucial organization-level resources were associated with an autonomy, followed by HR practices. Efficient HR practices are considered to be an efficient instrument for promotion of employees' well-being, while at the same time advancing an organization itself. On the group level, the authors found social support to be the most studied resource, followed by relatively few studies on team characteristics (Nielsen et al., 2017).

Transformational leadership and LMX theory were considered the most prominent leadership approaches promoting employee well-being and performance on a leader level (Arnold, Turner, Barling, Kelloway \& McKee, 2007).

On the individual level the most studied resources regarding employee well-being and performance were related to Psychological Capital construct, namely self-efficacy, hope, optimism, and resilience (Avey, 2014).

Promotion of employee well-being at the workplace and stimulation of their efficiency should be conducted on different levels. Thus, it is important to foster in employees such qualities as self-efficacy, which can help in establishing the right level of autonomy for employees. These qualities can be stimulated by transformational leadership style, as well as proper HRM practices. At the same time, on the group level it is important that employees can establish such social connections that foster openness and mutual support.

\section{Research Methodology}

\section{Sample}

The sample consisted of 22 female and 30 male participants from Germany, Austria, and Croatia aged 23 to 58 years ( $M$ $=37.42, S D=10.69$ ) who are in full-time employment. We randomly allocated groups to one of the two experimental conditions. 
The attendants were volunteers, did not receive any payment or credit for their collaboration and were recruited through direct contact (either by asking fellows directly or by getting in contact through mail or phone after announcing about the planned study). All participants gave written, informed consent before participating in the study.

Participants with a history of neurological disease were excluded from the experiment.

Design

To study the efficacy of different technologies (virtual realities on the way they are conveyed) on stress reduction and relaxation, a between-subjects design with two experimental conditions and repeated measurements (pre- and postquestionnaires) was used. We compared the following conditions:

REALEX Condition: subjects were presented with different natural environments on stand-alone VR glasses (Oculus Go, Samsung VR technology, Quad-ICD monitor with Fast Switch) with integrated spatial audio. Video Streaming Condition: equivalent video streaming of the platform YouTube was presented on a laptop (MacBook Air, 13,3"). It should be noted that the REALEX system used for this study presented $360^{\circ}$ videos made for the purpose of relaxation based on presurveys.

The classification of the conditions and an overview of the socio-demographic questions can be seen in Table 1.

Table 1

Sociodemographic data of the REALEX and the video streaming condition

\begin{tabular}{lll}
\hline & REALEX & Video streaming \\
$n=31$ & $n=21$ \\
\hline Age in years & $39.16(9.29)$ & $34.86(12.27)$ \\
Gender & $14: 17$ & $8: 13$ \\
(female:male) & & \\
\hline
\end{tabular}

Note. Values are means (SD)

The content of the two conditions included various nature recordings (snowy landscapes, view of a lake, view of a bridge near a lake), each accompanied by nature sounds (birdsong, breeze, water noise, rippling brook). The videos differed neither in their length nor in the way they were presented visually or audibly.

\section{Measures}

In addition to the socio-demographic questionnaire, which also recorded the current stress load, its causes and previous experiences with media in virtual reality, different types of self-reported measures to evaluate (1) their mood (dependent variables with special focus on relaxation) before and after the media experience and (2) their feeling of presence during a VR experience (is levied after the intervention) were used before and after the virtual experience for each participant:

Visual Analogue Scale (VAS; Gross \& Levenson, 1995). Participants are required to indicate how they feel at the specific moment of the questioning concerning each of seven ten-point visual analogue scales (where $1=$ "I'm not feeling the emotion at all" to $10=$ "I feel the emotion very strongly") measuring the six basic emotions happiness, fear, anger, disgust, surprise and contempt according to Ekman (Ekman, 1992) and an added item for relaxation, which should record the degree of relaxation experienced before and after the intervention.

Positive and Negative Affect Schedule (PANAS; Watson, Clark \& Tellegen, 1988). This questionnaire measures the positive and negative affects through ten positive (which compose the global Positive Affect Score) and ten negative (which compose the global Negative Affect Score) emotion adjectives. Survey Participants are required to indicate the extent to which they feel the emotions on a five-point scale (where $1=$ "very slightly" or "not at all" to 5 = "extremely"). 
The short-form version of the Depression Anxiety Stress Scales (DASS-21; Lovibond \& Lovibond, 1995). This 21-item screening and dimensional severity measurement scale measures the presence of anxiety, depressive and stress states. It contains three seven-item subscales: anxiety, depression, and stress subscale, each item being scored on a four-point scale (where $0=$ "does not apply at all" to $3=$ "strongly accurate" or "applies most of the time").

The UCL Presence Questionnaire (Slater, Usoh \& Steed, 1994) as a post-experience subjective measure was presented to the participants to capture the feeling of presence after the virtual reality experience. Respondents are required to provide ratings on a seven-point Likert scale on three questions like for example Q1: "Rate your sense of being in the virtual environment'.

\section{Procedure}

At the beginning of the intervention, the subjects were asked to relax for five minutes and refrain from all activities to ensure a baseline of relaxation. Subsequently, the persons were instructed to fill in the first pre-questionnaires (Sociodemographic Questionnaire, VAS, PANAS, DASS), after which the participants were instructed about the use of the equipment in the REALEX condition, their possibilities to explore the virtual environment (turn head 180 degrees to discover the whole natural scene), and the intervention of about ten minutes was carried out. After the virtual experience, the post-questionnaires (VAS, PANAS, DASS, UCL Presence Questionnaire) were presented. The study took place daily between 11 am and 6 pm.

\section{Results}

Data were analyzed using IBM SPSS 25.0.0.1 with $a=.05$ for all statistical tests. Preliminary data analysis with skewness and kurtosis showed that the video streaming condition scores were distributed normally, for the REALEX condition this was waived due to the central limit theorem. Using 1D-boxplots no outlier was found in both conditions and therefore all values were included in the calculations.

A two-factorial ANOVA with the within-subjects factor measurement time, consisting of the focused relaxation values of the VAS at times $t_{1}$ and $t_{2}$, and the between-subjects factor condition, divided into the two representations of virtual reality through the REALEX $360^{\circ}$ glasses and the video streaming, shows a significance in the main effect measurement time $\left(F(1,50)=11.369, p=.001, \eta_{p}^{2}=.185\right)$ so that the relaxation is higher after the intervention $(M=6.15, S D=2.57)$ than before $(M=4.89, S D=2.24)$, but no significant interaction between the measurement time and the condition $(F(1,50)=$ $\left.1.394, p=.243, \eta_{p}^{2}=.027\right)$. In another two-factorial ANOVA with the within-subjects factor measurement time of the values of the stress subscale of the DASS at times $t_{1}$ and $t_{2}$ and the between-subject factor condition of the two intervention types, a significant difference was also found in the main effect measurement time $\left(F(1,50)=29.97, p<.001, \eta_{p}^{2}=.375\right)$ so that the stress value is higher before the intervention $(M=6.04, S D=3.88)$ than after the intervention $(M=4.15, S D=3.58)$, but no significance was found in the interaction $\left(F(1,50)=1.337, p=.253, \eta_{p}^{2}=.026\right)$.

Despite the non-significant interactions, we examined the measurement times of the two conditions to detect different trends between the conditions (Table 2 and Table 3). A stress reduction (DASS stress subscale), as well as an increase in relaxation (VAS relaxation), could be achieved in both conditions, but the greatest trend to a stress reduction was achieved in the virtual reality with REALEX.

Table 2. Relaxation (VAS) and Stress (DASS) Ratings before and after the exploration of the virtual environment in the REALEX condition

\begin{tabular}{|c|c|c|c|c|c|c|c|}
\hline \multirow[t]{2}{*}{ Measure } & \multicolumn{2}{|l|}{$\mathrm{t}_{1}$} & \multicolumn{2}{|l|}{$t_{2}$} & \multirow[t]{2}{*}{$t(30)$} & \multirow[t]{2}{*}{$p$} & \multirow[t]{2}{*}{ Cohen's d } \\
\hline & $M$ & $S D$ & $M$ & $S D$ & & & \\
\hline $\begin{array}{l}\text { VAS } \\
\text { Entspannung }\end{array}$ & 5.03 & 2.17 & 6.52 & 2.59 & -3.473 & .002 & 0.624 \\
\hline
\end{tabular}



DASS
5.77
3.48
3.58
2.85
4.720
$<.001$
0.848

Skala Stress

Table 3. Relaxation (VAS) and Stress (DASS) Ratings before and after the exploration of the virtual environment in the video streaming condition

\begin{tabular}{|c|c|c|c|c|c|c|c|}
\hline \multirow[t]{2}{*}{ Measure } & \multicolumn{2}{|l|}{$t_{1}$} & \multicolumn{2}{|l|}{$t_{2}$} & \multirow[t]{2}{*}{$t(20)$} & \multirow[t]{2}{*}{$p$} & \multirow[t]{2}{*}{ Cohen's $d$} \\
\hline & $M$ & $S D$ & $M$ & $S D$ & & & \\
\hline $\begin{array}{l}\text { VAS } \\
\text { Entspannung }\end{array}$ & 4.90 & 2.39 & 5.62 & 2.50 & -1.492 & .151 & 0.325 \\
\hline $\begin{array}{l}\text { DASS } \\
\text { Skala Stress }\end{array}$ & 6.43 & 4.47 & 5.00 & 4.38 & 3.423 & .003 & 0.747 \\
\hline
\end{tabular}

During subsequent calculations, no further statistical significance was found in the interactions between the measurement time* condition. The difference values of the instruments (VAS, PANAS, DASS) that were collected but are not the focus of this study are shown in Table 4.

In the further observations of the individual conditions, only the condition REALEX showed (after the alpha error correction by Bonferroni-Holm) a significant change in the anger indicated on the visual analogue scale: subjects of this condition showed higher values before the intervention $(M=1.65, S D=2.68)$ than after the intervention $(M=0.81, S D=1.99 ; t(30)$ $=3.353, p=.002$ ).

Table 4. Changes in the other measurements (VAS, PANAS, DASS) over $t_{1}$ and $t_{2}$

\begin{tabular}{lllllllll}
\hline Measurement & \multicolumn{7}{l}{ REALEX } & \multicolumn{7}{c}{ Video Streaming } \\
\cline { 2 - 9 } & $\mathrm{t}_{1}$ & & $\mathrm{t}_{2}$ & & $\mathrm{t}_{1}$ & & $\mathrm{t}_{2}$ & \\
\hline \multirow{2}{*}{ VAS Questionnaire } & $\mathrm{M}$ & $\mathrm{SD}$ & $\mathrm{M}$ & $\mathrm{SD}$ & $\mathrm{M}$ & $\mathrm{SD}$ & $\mathrm{M}$ & $\mathrm{SD}$ \\
Happiness & & & & & & & & \\
Fear & 6.42 & 2.06 & 7.00 & 2.08 & 6.00 & 2.39 & 5.86 & 2.63 \\
Anger & 1.26 & 1.57 & 0.71 & 1.35 & 2.10 & 2.51 & 1.14 & 2.08 \\
Disgust & 1.65 & 2.68 & 0.81 & 1.99 & 1.52 & 2.21 & 0.62 & 1.12 \\
Surprise & 1.10 & 2.18 & 0.48 & 1.50 & 1.14 & 2.46 & 0.48 & 0.87 \\
Contempt & 2.45 & 2.45 & 3.10 & 3.18 & 3.24 & 3.25 & 2.52 & 2.93 \\
Relaxation & 1.23 & 2.46 & 0.52 & 1.63 & 1.38 & 1.86 & 0.52 & 0.98 \\
& 5.03 & 2.17 & 6.52 & 2.59 & 4.90 & 2.39 & 5.62 & 2.50
\end{tabular}

PANAS Questionnaire

Positive Affect

$\begin{array}{lll}2.06 & 0.61 \quad 2.07\end{array}$

0.75

1.83

0.73

1.74

0.86

Negative Affect

$0.43 \quad 0.58$

0.25

0.45

0.61

$0.67 \quad 0.41$

0.69

DASS Questionnaire 


\begin{tabular}{lllllllll} 
Subscale Depression & 2.58 & 2.35 & 1.94 & 2.08 & 3.81 & 4.26 & 3.24 & 4.02 \\
Subscale Anxiety & 2.68 & 2.82 & 1.90 & 2.23 & 2.48 & 2.79 & 1.95 & 2.84 \\
Subscale Stress & 5.77 & 3.48 & 3.58 & 2.85 & 6.43 & 4.47 & 5.00 & 4.38 \\
\hline
\end{tabular}

\section{Comparison with video streaming}

In a direct comparison of the conditions, clear trends towards an improved stress reduction as well as an increased relaxation induction through the $360^{\circ}$ medium compared to conventional relaxation videos can be seen despite nonsignificant differences. This tendency is also apparent concerning the role of the present experience (measured by the UCL Presence Questionnaire) during the experiment: although there are no statistical differences between the conditions, people who experienced virtual realities through REALEX $(M=3.75, S D=.91)$ tended to show higher values than people who streamed video $(M=3.25, S D=1.16 ; t(50)=1.735, p=.089)$.

Main Causes of Stress and Stress improvements

The current level of stress load (based on the day of the survey, including the last seven days) recorded during the pre-test showed that $58 \%$ of the participants felt frequently or even constantly stressed, $38 \%$ reported an occasional stress load, and only $4 \%$ reported a never occurring stress level. In a further item, which was intended to record the possible causes of the current stress load, it was shown that $94 \%$ of the respondents see the causality in the occupational context and here (multiple answer set) particularly due to deadline or time pressure (83\%), conflicts with colleagues $(23 \%)$, an unsatisfactory working environment $(21 \%)$ or a general dissatisfaction in the occupational context $(21 \%)$.

Based on the existing literature as well as the available results, it is shown that a reduction of the prevailing stress level as well as an increase in relaxation can be achieved through the presentation of virtual natural environments. In the condition REALEX, $64.5 \%$ also stated that they could (very well) imagine using the programme during their work break in a professional environment.

\section{Discussion \& Conclusion}

The present study was able to show that the immersive character of virtual reality solutions also translates well to the field of relaxation and to the business environment. While a small number of older studies exist that show similar results - the generally beneficial effect of VR based relaxation programs - they mostly focused on clinical samples. In those samples, in general a positive relaxation effect could be proven. However, most of the studies conducted before lacked the use-case described within this study. In the light of stress and stress-related illnesses being among the most prominent problems in the HR world and in regards to employee well-being, a system that can improve this situation can be seen as a valuable tool of HR management.

While the present study of course is not able to showcase long-term effects on employee's morale, motivation or general burn-out risk, the effects show clearly that the (even short-term) usage of a VR based relaxation system can benefit employees' well-being. The comparison with classic video-streaming revealed, that it not only the general digital presentation of natural environments, that benefits the well-being, but that this general effect is strongly amplified by the deep immersion provided by virtual reality.

\section{References}

[1] Arnold, K. A., Turner, N., Barling, J., Kelloway, E. K., \& McKee, M. C. (2007). Transformational leadership and psychological well-being: the mediating role of meaningful work. Journal of occupational health psychology, 12(3), 193-203. 
[2] Avey, J. B. (2014). The left side of psychological capital: New evidence on the antecedents of PsyCap. Journal of Leadership \& Organizational Studies, 21(2), 141-149.

[3] Baños, R. M., Espinoza, M., García-Palacios, A., Cervera, J. M., Esquerdo, G., Barrajón, E., \& Botella, C. (2013). A positive psychological intervention using virtual reality for patients with advanced cancer in a hospital setting: a pilot study to assess feasibility. Supportive Care in Cancer, 21(1), 263-270.

[4] Booth, R., \& Rachman, S. (1992). The reduction of claustrophobia-I. Behaviour Research and Therapy, 30(3), 207-221.

[5] Darling, J. R., \& Heller, V. L. (2011). The key for effective stress management: Importance of responsive leadership in organizational development. Organization Development Journal, 29(1), 9.

[6] Ekman, P. (1992). An argument for basic emotions, Cognition and Emotion, 6(3-4), 169-200.

[7] European Commision. (2010). Health and safety at work in Europe. Retrieved from https://ec.europa.eu/eurostat/documents/3217494/5718905/KS-31-09-290-EN.PDF/88eef9f7-c229-40de-b1cd$43126 \mathrm{bc4a946.}$

[8] Eurofound. (2012). Fifth European Working Conditions Survey. Luxembourg: Publications Office of the European Union.

[9] Gross, J. J., \& Levenson, R. W. (1995). Emotion elicitation using films. Cognition and Emotion, 9, 87-108.

[10] Herrero, R., Garcia-Palacios, A., Castilla, D., Molinari, G., \& Botella, C. (2014). Virtual reality for the induction of positive emotions in the treatment of fibromyalgia: a pilot study over acceptability, satisfaction, and the effect of virtual reality on mood. Cyberpsychology, Behavior, and Social Networking, 17(6), 379-384.

[11] Lovibond, S. H., \& Lovibond, P. F. (1995). Manual for the depression anxiety stress scales. Sydney: Psychology Foundation.

[12] Luthans, F., \& Youssef, C. M. (2004). Human, social, and now positive psychological capital management: Investing in people for competitive advantage. Organizational Dynamics, 33(2), 143-160.

[13] Makransky, G., Terkildsen, T. S., \& Mayer, R. E. (2019). Adding immersive virtual reality to a science lab simulation causes more presence but less learning. Learning and Instruction, 60, 225-236.

[14] Michie, S. (2002). Causes and management of stress at work. Occupational and environmental medicine, 59(1), 67-72.

[15] Nielsen, K., Nielsen, M. B., Ogbonnaya, C., Känsälä, M., Saari, E., \& Isaksson, K. (2017). Workplace resources to improve both employee well-being and performance: A systematic review and meta-analysis. Work \& Stress, 31(2), 101-120.

[16] Rothbaum, B. O., Hodges, L. F., Kooper, R., Opdyke, D., Williford, J. S., \& North, M. (1995). Virtual reality graded exposure in the treatment of acrophobia: A case report. Behavior therapy, 26(3), 547-554.

[17] Schulte, P., \& Vainio, H. (2010). Well-being at work-overview and perspective. Scandinavian journal of work, environment \& health, 36(5), 422-429.

[18] Serrano, B., Baños, R. M., \& Botella, C. (2016). Virtual reality and stimulation of touch and smell for inducing relaxation: A randomized controlled trial. Computers in Human Behavior, 55, 1-8.

[19] Slater M., Usoh M., \& Steed A. (1994) Depth of presence in virtual environments. Presence Teleoperators \& Virtual Environments, 1, 130-144.

[20] Slater, M., \& Sanchez-Vives, M. V. (2016). Enhancing our lives with immersive virtual reality. Frontiers in Robotics and Al, 3, 74.

[21] Thoondee, K. D., \& Oikonomou, A. (2017). Using virtual reality to reduce stress at work. In 2017 Computing Conference. London: IEEE.

[22] Tuomi, K., Vanhala, S., Nykyri, E., \& Janhonen, M. (2004). Organizational practices, work demands and the well-being of employees: a follow-up study in the metal industry and retail trade. Occupational Medicine, 54(2), 115-121. 
[23] Vasantha, M. P., \& Reddy, M. P. (2017). Stress at work place: Causes, consequences and remedies. International Journal of Research in Economics and Social Sciences (IJRESS), 7(9), 95-104.

[24] Watson, D., Clark, L. A., \& Tellegen, A. (1988). Development and validation of brief measures of positive and negative affect: The PANAS scales. Journal of Personality and Social Psychology, 54, 1063-1070. 